\title{
Temperament and Anxiety of Children in Childcare Centre: Child-Parent Relationship as Mediator
}

\author{
Low Biam Hong \\ Dr. Zarinah Arshat \\ Dr. Siti Nor Yaacob \\ Department of Human Development and Family Studies \\ Faculty of Human Ecology \\ Universiti Putra Malaysia \\ Malaysia
}

\begin{abstract}
The present study was conducted to determine the relationships between child temperament and anxiety with child-parent relationship as mediator among children in childcare centers in Selangor, Malaysia. A total of 319 mothers with children aged between 3 to 6 years old were participated in the study. The findings revealed that both child's sociability and close child-parent relationship had significant negative relationship with child's anxiety symptom. Emotional children had significant higher levels of child's anxiety symptom. Closeness childparent relationship was fully mediated in child emotionality with anxiety and also child sociability with anxiety.
\end{abstract}

Keywords: Child's temperament, child-parent relationship, anxiety, childcare center

\subsection{Introduction}

Nowadays many parents send their children for childcare service when they are at work in Malaysia (Pheng, 2007). The demand may reflect from the number of childcare centers in Malaysia, and based on the national record there were 1,395 registered childcare centers and approximately 7,000 childcare centers that have yet to register with the Ministry of Women, Family and Community Development (Department of Social Welfare Malaysia, 2012). Toddlers are in the midst of learning communication skills, and high child-to-staff ratio in childcare centers may overlook this demand which may result with worsening anxious children in distress and self-consciousness (Coplan \& Arbeau, 2008).

Anxiety can be defined as future-oriented emotion and is characterized as uncontrollable perceptions and unpredictability over potentially aversive events, and a fast shift in attention to the focus of potentially risky events or one's own emotional response to these events (Astrom, Wiberg, Sircova, Wiberg \& Carelli, 2014). Anxiousness can be ranged from very low levels to high levels and it may influence one's social, personal and academic performance (Rajchert, Zoltak \& Smulczyk, 2013). While temperament can be defined as individual's response to the environment (Parke \& Gauvain, 2009). It partially appears during infancy and fully appears by preschool age (Zentner \& Bates, 2008). Child's temperament is one of the significant factors that can cause a child's anxiety (Hudson, Dodd \& Bovopoulos, 2011; Lindhout, Markus, Hoogendijk \& Boer, 2009; Volbrecht \& Goldsmith, 2010). Children with difficult temperaments tend to be shy and not adaptable to new people and environment, and so as a result, difficult children tend to have higher anxiety levels (Schultz, 2008) and less closeness with their parents (Scopesi, Viterbori, Sponza \& Zucchinetti, 2004).

According to Bronfenbrenner's ecological system theory, the microsystem has a direct interaction (eg. the direct contact of a child with peers as well as a child with caregiver) with the children, thus it has the greatest impact on children's developmental outcome. Specifically, the child's temperament and child-parent relationship have a direct interaction with child's anxiety (Hudson, Dodd \& Bovopoulos, 2011; Shamir-Essakow, Ungerer \& Rapee, 2005). Child-parent relationship is a mutual relationship between parents and child, and both parents and child play a crucial role in the formation of child-parent relationship (Pianta, 1997). Belsky's process model (Belsky, 1984) suggested that a child's developmental outcome could be affected by the mutual result of parental behaviour and child rearing style. 
The nature of the child (the child's temperament) will influence the formation of child-parent relationship and this interaction may influence the child's development outcome, which include child's anxiety (Brumariu, Kerns \& Seibert, 2012).

The study conducted by Chiah and Baharudin (2012) among early adolescents in Malaysia revealed that both positive and negative affectivity temperament dimensions is significantly associated with parental attachment; parental attachment also is significantly related to socioemotional adjustments (both strengths and difficulties). Whereas, only positive affectivity temperament dimension is significantly associated with strengths in socioemotional adjustment; and only negative affectivity temperament dimension was found significantly related to difficulties in socioemotional adjustment. Parental attachment was found to partially mediate the relationship between positive affectivity temperament dimension and strengths socioemotional adjustment; as well as negative affectivity temperament dimension and difficulties socioemotional adjustment. Fully mediating effect on parental attachment was found between the relationship of positive affectivity temperament dimension and difficulties socioemotional adjustment; and negative affectivity temperament dimension and strengths socioemotional adjustment. These findings implied that parental attachment could buffer the effect of specific temperament dimension on certain aspect of adjustments.

Hudson, Dodd and Bovopoulos (2011) studied the association between behavioral inhibition, family environment and anxiety among 202 preschool children. The study result indicated that children with inhibited behaviors are more likely to meet the criteria of anxiety diagnoses. The finding also revealed that parenting and child-parent relationship were significant associated with a child's inhibited behaviors. Even when there were no interactions between temperament and family environment in child's anxiety, there was relationship with child's anxiety after controlling behavioral inhibition.

Similar results were found in other previous studies, where the child's behavioral inhibition and child-parent relationship had an interactive effect on anxiety symptomatology (Muris, Brakel, Arnt\& Schouten, 2011). Study conducted by Shamir-Essakow, Ungerer and Rapee (2005) revealed that insecure child-parent relationship and behavioral inhibition were associated with child's anxiety among 3 to 4 years old children. Child-parent relationship may raise the possibility of the transformation from temperamental proneness to anxiety disorder.

Moreover, in a 3.8 year longitudinal research on 425 children aged between 6-9 years old in Beijing, researchers have found that over controlling parents have a higher prediction of child internalizing problems (Muhtadie, Zhou, Eisenberg \& Wang, 2013). The result suggested that children with low effortful control may be mainly predisposed to the adverse outcome of over controlled parents. The findings of a longitudinal study conducted by Lewis-Morrarty and colleagues (2012) found that consistent high behavioral inhibition in a child significantly predicted higher adolescent social anxiety symptoms in the presence of high maternal over-control across childhood development. Likewise, findings by Brumariu and Kerns (2013) illustrated that children with close child-parent relationships had lower levels of anxiety, and children with higher levels of negative emotionality of shyness tend to be anxious. The result indicated that both temperament and child-parent relationship predicted child's anxiety.

Dallaire and Weinraub (2005) found that children with conflicts in child-parent relationship reported higher levels of separation anxiety than children with close child-parent relationship. Their study also demonstrated that infantmother attachments and the mother's sensitivity have a playing role in predicting children's separation anxiety. Study conducted by Hazen (2005) discovered that adolescents' (11 to 15 years old) interactive models of temperament predicting anxious and depressive symptoms, and high levels of effortful control may buffer adolescents from experiencing internalizing symptoms. The interaction of effortful control and maternal rejection was statically a significant predictor of anxious symptoms.

Nevertheless, findings on children between 11 to 15 years old revealed positive correlation on behavioral inhibition, child-parent relationship quality, and anxious and controlling behaviors as well as anxiety scores. Higher levels of behavioral inhibition, conflict child-parent relationship, maternal control and anxious rearing were associated with higher levels of anxiety symptoms (Brakel, Muris, Bogels \&Thomassen, 2006). On the contrary, a study group which focused on children between 7 to 12 years old and primarily consisted of Caucasians found opposite results. Affrunti, Geronimi and Woodruff-Borden (2013) found that parents' nurturing does not moderate the relation between a child's fearful temperament and child's anxiety. In another words, high levels of nurturing by parents may not serve as a protective variable in fearful temperaments and child's anxiety. 
Based on the literature review as discussed before, the aim of this study is to determine mediating role of childparent relationship between child's temperament and anxiety among children in childcare centers.

\subsection{Method}

\subsection{Participants}

There were 319 mothers who have children in private childcare centers in urban areas of Selangor fulfilled the criteria and being selected as focal respondents. Out of these participants, there were $42.6 \%$ of mothers below the age of 31 years old, with a mean of 31.63 years old. Most of the mothers completed their tertiary education, $36.1 \%$ of them with a diploma qualification (15 years of education), 38.2\% obtained their bachelor's degree qualification (16 years of education). $49.2 \%$ of 3 years old children involved in the study, with a mean age of $4.04,52 \%$ of them were male and $48 \%$ were female. Most of the children (73\%) were an only child or only had one sibling in the family, $71.8 \%$ of them came from family with RM3964.74 - RM9944.36 monthly income (M= RM6954.55).

\subsection{Data Collection}

Prior to data collection, consent was obtained from the registered private child-care center's principal. After obtaining consent, the researcher sent the consent forms to the parents to confirm their willingness to participate in the study and to inform them on the purpose and procedure of the research. All instruments in this study were translated using forward-backward translation procedure. The set of questionnaire was distributed to the mother through children in childcare centers.

\subsection{Measurements}

EAS Temperament Survey for Children (Buss \& Plomin, 1984) is a 20-item measure with a 4-point Likert scale from low (1) to high (4) used to assess child's temperament. This measure has four dimensions of child's temperament, namely emotionality (E), activity (A) and sociability and shyness (S). It has been used for clinical and community samples and it is recommended for children aged 1 to 9 years. The average internal consistency of four subscales is .78 (Boer \& Westernberg,1994), internal consistency for emotionality is .67, activity is .75, sociability is .79 and shyness is .60 (Mathiesen \& Tambs, 1999). The overall reliability of this measure in the present study is .67.

Child Parent Relationship Scale (CPRS) is used to measure on child-parent relationship (Pianta, 1997). CPRS is a 15 items parent self-report instrument, based on their perception to indicate their relationships with their sons or daughters. Conflict and Closeness are the two subscales in CPRS, respondents self-rating themselves in 5-point Likert scale (from $1=$ definitely does not apply to $5=$ definitely applies). Conflict ( 8 items) subscale measures the degree of negativity relationship of parent with particular child, the Cronbach alphas for conflict subscale was reported as .84 (Pianta, 1997). Where closeness (7 items) assesses the extent of warmth, affection and open communication of child-parent relationship, the reliability was reported as .72 (Pianta, 1997). The overall reliability of CPRS in the current study is .73.

Spence Preschool Anxiety Scale (SPAS) (Spence, Rapee, McDonald, \& Ingram, 2001) is used to assess anxiety. This instrument is designed to assess the symptoms of anxiety and fears of young children below the age of 6 . SPAS consists of 28 items in 5 point Likert scale (from not true at all to very often true) which required parents to rate for children. SPAS measures four type of anxieties, namely generalized anxiety, social anxiety, separation anxiety and specific fear. This instrument is reported to have reliability ranged from .54 to .88 , which considered reliable (Spence, Rapee, McDonald, \&Ingram, 2001). The reliability of SPAS is reported as .92 in the current study.

\subsection{Result}

\subsection{Relationship between Child's Temperament, Child-Parent Relationship with Child's Anxiety}

Based on the findings shown in Table 1, an emotional child was found to be significant negatively correlated with child-parent relationship $(r=-.33, p<.01)$ Furthermore, children with higher levels of emotionality temperament characteristic have also shown significantly high levels of child's anxiety symptom $(r=.25, p<.01)$ in the current study. The study also revealed that child's sociability has shown significant correlation with child-parent relationship $(\mathrm{r}=.18, \mathrm{p}<.01)$. There was a negative significant association found between child's sociability with a child's anxiety symptom $(\mathrm{r}=-.15, \mathrm{p}<.01)$, which indicated sociable children have lower levels of child's anxiety symptom. 
On the other hand, a child's shyness was found to be significant negatively correlated with child-parent relationship $(\mathrm{r}=-.21, \mathrm{p}<.01)$. The findings illustrated that child-parent relationship was significant negatively correlated with child's anxiety symptom $(r=-.52, p<.01)$.

Table 1: Correlations between Child's Temperament, Child-Parent Relationship and Child's Anxiety

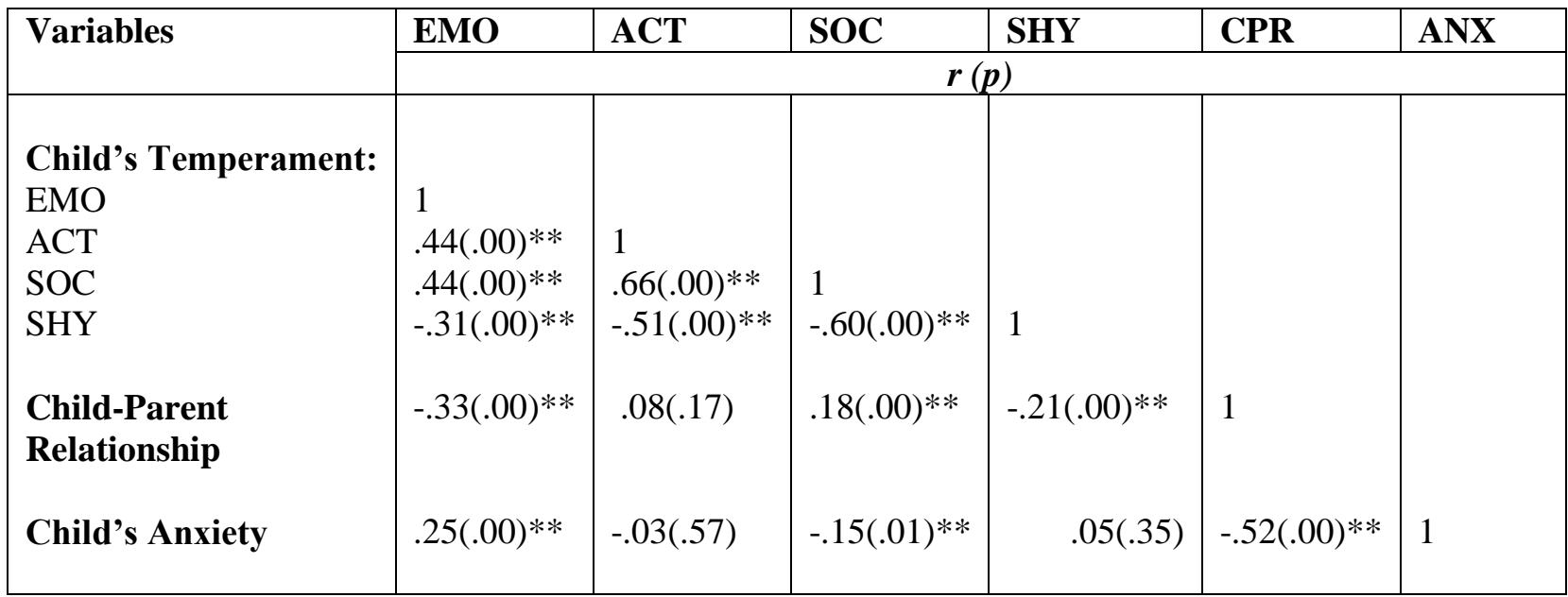

Note: $* p<.05, \quad * * p<.01, \quad \mathrm{EMO}=$ Emotionality, $\mathrm{ACT}=$ Activity, $\mathrm{SOC}=$ Sociability, SHY $=$ Shyness, $\mathrm{CPR}=$ Child-Parent Relationship, $\mathrm{ANX}=$ Anxiety

\subsection{Relationship between Child's Emotionality and Anxiety Mediated by Child Parent Relationship}

Prior to determining the mediating effects between independent variable and dependent variable, a series of simple linear regression analysis were performed as four step approach proposed by Baron and Kenny (1986). In the previous correlation analyses, child's activity and shyness temperament characteristic were unrelated to anxiety. The study thus, failed to illustrate the mediating role of child-parent relationship in relating child's activity and shyness temperament characteristic with anxiety.

The study revealed that the relationship between child's emotionality and anxiety is fully mediated by childparent relationship. As shown in the fourth regression equations in Table 2, the direct relationship of child's emotionality to anxiety dropped to be non-significant when child-parent relationship were controlled, which indicated perfect mediation relationship. The Sobel test was also calculated to provide the significance of the indirect effect of child's emotionality on anxiety via child-parent relationship. By running the Sobel Test software program (Creswell, 2013), the statistical test was found to be -5.59 with statistical significance of p value of .00 . Hence, the findings suggested that much of the effect of child's emotionality on anxiety is indirect via childparent relationship. Figure 1 illustrates the mediation model of the relationship between child's emotionality and anxiety mediated by child-parent relationship.

Table 2: Relationship between Child's Emotionality and Anxiety Mediated by Child-Parent Relationship

\begin{tabular}{|l|l|l|l|l|l|l|l|}
\hline Step & DV & IV & B & SE & $\boldsymbol{B}$ & $\boldsymbol{t}$ & $\boldsymbol{P}$ \\
\hline 1 & Child's Anxiety & Child's Emotionality & .97 & .22 & $.25^{* *}$ & 4.50 & .00 \\
2 & Child-Parent Relationship & Child's Emotionality & -.47 & .07 & $-.33^{* *}$ & -6.30 & .00 \\
3 & Child's Anxiety & Child-Parent Relationship & -1.48 & .14 & $-.52^{* *}$ & -10.95 & .00 \\
\hline 4 & Child's Anxiety & Child's Emotionality & .31 & .20 & .08 & 1.56 & .12 \\
& & Child-Parent Relationship & -1.41 & .14 & $-.50 * *$ & -9.82 & .00 \\
\hline
\end{tabular}

Note: $* p<.05, * * p<.01$ 


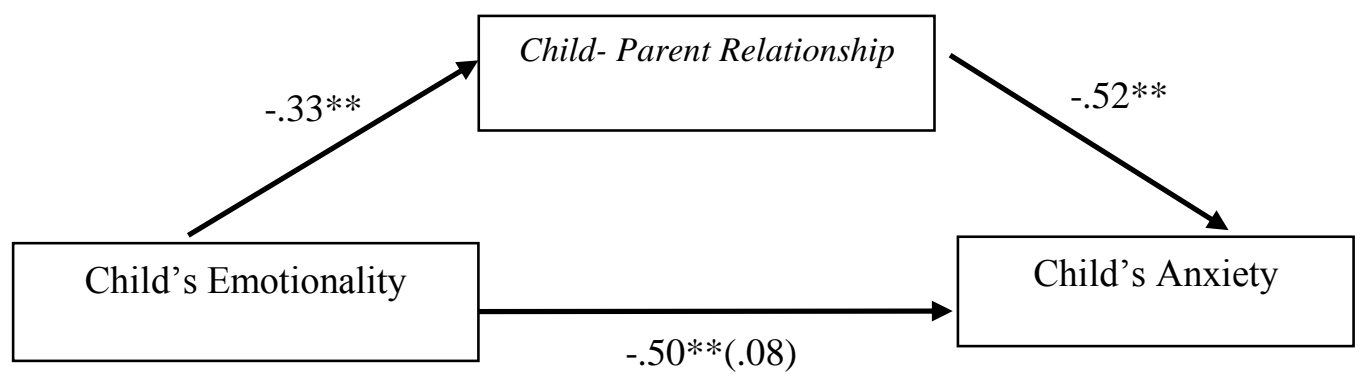

Figure 1: The Mediating Role of Child-Parent Relationship on the Relationship between Child's Emotionality and Anxiety

\subsection{Relationship between Child's Sociability and Anxiety Mediated by Child-Parent Relationship}

Table 3 disclosed the completely mediating effect in the relationship of child's sociability and anxiety through child-parent relationship. When child-parent relationship was controlled, the direct relationship of child's sociability and anxiety dropped to be non-significant. Sobel statistical test was found to be -3.06 at statistical significance of $\mathrm{p}$ value at .00 . This result indicated that much of the effect of child's sociability on anxiety is mediated by child-parent relationship.

Table 3: Relationship between Child's Sociability and Anxiety Mediated by Child-Parent Relationship

\begin{tabular}{|c|c|c|c|c|c|c|c|}
\hline Step & DV & IV & B & SE & $B$ & $t$ & $P$ \\
\hline 1 & Child's Anxiety & Child's Sociability & -.77 & .29 & $-.15 * *$ & -2.65 & .01 \\
\hline 2 & $\begin{array}{l}\text { Child-Parent } \\
\text { Relationship }\end{array}$ & Child's Sociability & .32 & .10 & $.18 * *$ & 3.19 & .00 \\
\hline 3 & Child's Anxiety & $\begin{array}{l}\text { Child-Parent } \\
\text { Relationship }\end{array}$ & -1.48 & .14 & $-.52 * *$ & -10.95 & .00 \\
\hline 4 & Child's Anxiety & $\begin{array}{l}\text { Child's Sociability } \\
\text { Child-Parent } \\
\text { Relationship }\end{array}$ & $\begin{array}{l}-.29 \\
-1.45\end{array}$ & $\begin{array}{l}.25 \\
.14\end{array}$ & $\begin{array}{l}-.06 \\
-.51 * *\end{array}$ & $\begin{array}{l}-1.16 \\
-10.58\end{array}$ & $\begin{array}{l}.25 \\
.00\end{array}$ \\
\hline
\end{tabular}

Note: Significant level $=* p<.05, * * p<.01$

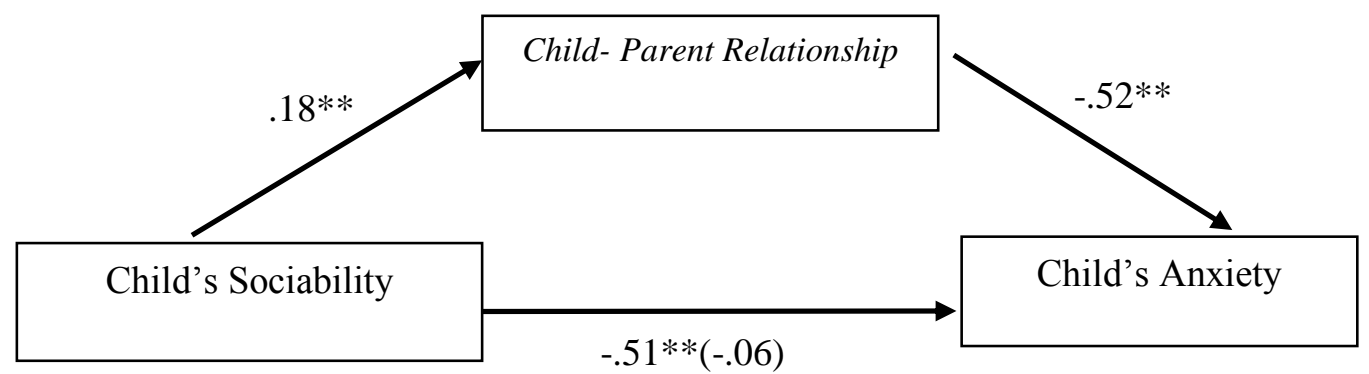

Figure 2: The Mediating Role of Child-Parent Relationship on the Relationship between Child's Sociability and Anxiety

\subsection{Discussion and Implication}

Results of the study provided evidence that those children with high levels of emotionality temperament characteristics were less close with their mother and have high levels of anxiety symptom. This finding is congruent with previous research (Laibe, Panfile, \&Makariev, 2008; Sokolowski \& Bost, 2005) which proved that an emotional child finds it difficult to form closer child-parent relationship. Current study demonstrated that a sociable child was more likely to form closer child-parent relationship and have lower levels of anxiety symptom. Children with positive temperament characteristics could make more social bids with people around, which results in better quality child responsiveness in the formulation of child-parent relationship (Wilson \& Durbin, 
2012). Sociable children also are less likely to be described as the personal character of anxious children (Lindhout, Markus, Hoogendijk\& Boer, 2009).Moreover, child-parent relationship was found to serve as a mediator in relating child's temperament (emotionality and sociability) with anxiety.

This disclosed child-parent relationship could buffer the effect of a child's temperament on anxiety. According to Process Model, the factors influencing parental behaviour may affect child rearing and it eventually influences the outcome of child development. Based on this logic, it highlighted the significance relevance of child-parent relationship between child's temperament and anxiety.

For theoretical implementations, the findings of this study are consistent with Bronfenbrenner's Ecological System Theory and Belsky's Process Model. According to Ecological System Theory, the individual's development is highly influenced by the interactions within the environment of family setting, community setting, cultural values, government's principles and laws. The present study emphasises on examining the child's biological characteristics (child's temperament) and the immediate context (child-parent relationship) influence on child's anxiety. In the terms of Ecological System Theory, the child's temperament and child-parent relationship are labelled under the micro system. The micro system is the most influential level of the ecological system theory as the individual's responses to the people in microsystem will affect how they are treated in return.

There are several limitations inherent in the present study. Firstly, the present study employed survey research method for the analysis purpose, and survey research required respondents to answer the questionnaire at one point of time. Anxiety may start at a very young age and it may influence in the long-term throughout the development. Hence, longitudinal research is recommended to be carried out in future for better understanding on child's anxiety behaviour.

Furthermore, due to the study group being too young (3 to 6 years old), mothers were recruited as respondents in the study. Future studies may consider multiple sources to gather comprehensive information on the study variables, such as gathering information from parents, teachers, caregivers and also child him/herself. This will help to avoid respondent's biasness and observation research could be served as another support for the research findings.

Last but not least, future studies may enlarge the age group of children involved in the study. This could provide a clearer picture to distinguish child's anxiety in different ages and could help to develop effective intervention programmes to prevent child's anxiety, as the problem faced by different age groups may not be the same. Future research could expand the study by involving more diverse samples from different backgrounds to generalize the findings to the whole population in Malaysia.

\section{References}

Affrunti, N.W., Geronimi, E.M.C. \& Woodruff-Borden, J. (2014). Temperament, peer victimization, and nurturing parenting in child anxiety: A moderated mediation model. Child Psychiatry Human Devoplement, 45, 483-492. doi:10.1007/s10578-013-0418-2

Astrom, E., Wiberg, B., Sircova, A., Wiberg, M. \& Carelli, M. (2014). Insights into features of anxiety through multiple aspects of psychological time. Journal of Integrative Psychology and Therapeutics, 2(3). doi: $10.7243 / 2054-4723-2-3$

Baron, R.M. \& Kenny, D.A. (1986). The moderator-mediator variable distinction in social psychological research: Conceptual, strategic, and statistical considerations. Journal of Personality and Social Psychology, 51(6), 1173-1182. doi:10.1.1.169.4836

Belsky, J. (1984). The determinants of parenting: A process model. Child Development, 55(1), 83-96. doi:10.2307/1129836

Boer, F. \& Westernberg, P.M. (1994). The factor structure of the Buss and Plomin EAS Temperament Survey (Parental Ratings) in a Dutch sample of elementary school children. Journal of Personality Assessment, 62(3), 537-551. doi:10.1207/s15327752jpa6203_13

Brakel, A.M.L., Muris, P., Bogels, S.M., and Thomassen, C. (2006). A multifactorial model for the etiology of anxiety in non-clinical adolescents: Main and interactive effects of behavioral inhibition, attachment and parental rearing. Journal of Child and Family Studies, 15(5), 568-578. doi:10.1007/s10826-006-9061-x

Bronfenbrenner, U. (1979). The Ecology of Human Development. Harvard University Press. 
Brumariu, L.E. \& Kerns, K.A. (2013). Pathways to anxiety: Contributions of attachment history, temperament, peer competence, and ability to manage intense emotions. Child Psychiatry Human Development, 22, 504-515. doi:10.1017/S0954579409990344

Brumariu, L.E., Kerns, K.A. \& Seibert, A. (2012). Mother-child attachment, emotion regulation, and anxiety symptoms in middle childhood. Journal of the International Assocation for Relationship Research(19), 569-585. doi:10.1111/j.1475-6811.2011.01379.x

Buss, A. H., and Plomin, R. (1984). Temperament: Early developing personality traits. Hillsdale: Lawrence Erlbaum.

Chiah, W.Y. and Baharudin, R. (2012). Temperament and parental attachment on early adolescents' socioemotional adjustments. Proceedings of 2012 2nd International Conference on Humanities, Historical and Social Sciences (CHHSS 2012), 48, pp. 53-57. doi:10.7763/IPEDR

Coplan, R.J. \& Arbeau, K.A. (2008). The stresses of a "Brave New World": Shyness and school adjustment in kindergarten. Journal of Research in Childhood Education, 22(4), 377-389. doi:10.1080/02568540809594634

Creswell, J. W. (2013). Research Design: Qualitative, Quantitative, and Mixed Methods Approaches (4th ed.). SAGE Publications.

Dallaire, D.H. \& Weinraub, M. (2005). Predicting children's separation anxiety at age 6: The contributions of infant-mother attachment security, maternal sensitivity, and maternal separation anxiety. Attachment \& Human Development, 7(4), 393 - 408. doi:10.1080/14616730500365894

Department of Social Welfare. (2012). Official Portal Department of Social Welfare. Retrieved from List of Child Care Centre Registered: http://www.jkm.gov.my/jkm/index.php?r=portal/map\&map_type=01\&id=blB5RIVjdVRpSk9kTmVNY WFkWFJjdz09

Field, A. P. \& Davey, G. C. L. (2001). Conditioning models of childhood anxiety. In W. K. Silverman, \& P. A. Treffers, Anxiety Disorders in Children and Adolescents: (pp. 187-211). Cambridge: Cambridge University Press.

Gelfand, D. M. \& Drew, C. J. (2003). Understanding Child Behavior Disorders (4th ed.). United States: Thomson Learning.

Goodman, G., Stroh, M. \& Valdez, A. (2012). Do attachment representations predict depression and anxiety in psychiatrically hospitalized prepubertal children? Bulletin of the Menninger Clinic, 76(3), 260-289. doi:10.1521/bumc.2012.76.3.260

Hazen, R. (2005). Parental Rejection, Temperament, and Internalizing Problems. The Ohio State University . ProQuest Information and Learning Company.

Huberty, T. (2004). Anxiety and Anxiety Disorder in Children: Information for Parents. Indiana University. National Association of School Psychologists.

Hudson, J.L., Dodd, H.F., and Bovopoulos, N. (2011).Temperament, family environment and anxiety in preschool children. Journal of Abnormal Child Psychology, 39, 939-951. doi:10.1007/s10802-011-9502-x

Laible, D., Panfile, T. \& Makariev, D. (2008). The quality and frequency of mother - toddler conflict: Links with attachment and temperament. Child Development, 79(2), 426 - 443. doi:10.1111/j.1467-8624.2007.01134.x.

Lewis-Morrarty, E., Degnan, K. A., Chronis-Tuscano, A., Rubin, K. H., Cheah, C. L., Pine, D. S., \& Fox, N. A. (2012). Maternal over-control moderates the association between early childhood behavioral inhibition and adolescent social anxiety symptoms. Journal of Abnormal Child Psychology, 40, 1363-1373. doi:10.1007/s10802- 012-9663-2

Lindhout, I.E., Markus, M.T., Hoogendijk, T.H.G. \& Boer, F. (2009). Temperament and parental child-rearing style: Unique contributions to clinical anxiety disorders in childhood. European Child \& Adolescent Psychiatry, 18, 439-446. doi:10.1007/s00787-009-0753-9

Mathiesen, K.S. \& Tambs, K. (1999). The EAS temperament questionnaire - Factor structure, age trends, reliability, and stability in a Norwegian sample. Journal of Child Psychology and Psychiatry, 40(3), 431439. doi:10.1111/1469-7610.00460

Muhtadie, L., Zhou, Q., Eisenberg, N. \& Wang, Y. (2013). Predicting internalizing problems in Chinese children: The unique and interactive effects of parenting and child temperament. Development and Psychopathology, 25, 653-667. doi:10.1017/S0954579413000084 
Muris, P., Brakel, A.M.L., Arntz, A. \& Schouten, E. (2011). Behavioral inhibition as a risk factor for the development of childhood anxiety disorders: A longitudinal study. Journal of Child \& Family Studies, 20, 157-170. doi:10.1007/s10826-010-9365-8

Parke, R. D. \& Gauvain, M. (2009). Child Psychology (7th ed.). Boston: McGraw-Hill.

Pheng, L. S. (2007, June). Child care services in Malaysia. Exchange, The Early Leaders' Magazine, 82-84.

Pianta, R. C. (1997). Adult-child relationship processes and early schooling. Early Education and Development, 8(1), 11-26. doi:10.1207/s15566935eed0801_2

Rajchert, J., Zoltak, T. \& Smulczyk, M. (2013). Trait-anxiety's moderating role in predicting academic performance improvement in PISA. Polish Journal of Applied Psychology, 11(3), 73-92. Retrieved from

http://www.pjap.psychologia.uni.wroc.pl/sites/default/files/PJP_11_3_2013\%3B\%2073-91_0.pdf

Schultz, D. P. (2008). Theories of Personality. Belmont, CA: Wadsworth.

Scopesi, A., Viterbori, P., Sponza, S. \& Zucchinetti, P. (2004). Assessing mother-to-infant attachment: the Italian adaptation of a self-report questionnaire. Journal of Reproductive and Infant Psychology, 22(2), 99-109. doi:10.1080/0264683042000205963

Shamir-Essakow, G., Ungerer, J.A. \& Rapee, R. M. (2005). Attachment, behavioral inhibition, and anxiety in preschool children. Journal of Abnormal Child Psychology, 33(2), 131-143. doi:10.1007/s10802-005$1822-2$

Sokolowski, M.S. \& Bost, K.K. (2005). Attachment, temperament, and preschool children's peer acceptance. Social Development, 14(3), 379-397. doi:10.1111/j.1467-9507.2005.00307.x

Spence,S.H., Rapee,R.,McDonald,C.\&Ingram, M. (2001).The structure of anxiety symptoms among preschoolers. Behaviour Research and Therapy, 39(11), 1293-1316. doi:10.1016/S0005-7967(00)00098-X

Volbrecht, M. M. \& Goldsmith, H. H. (2010). Early temperamental and family predictors of shyness and anxiety. Developmental Psychology, 46(5), 1192-1205. doi:10.1037/a0020616

Wilson, S. \& Durbin, C.E. (2012). Dyadic parent-child interaction during early childhood: Contributions of parental and child personality traits. Journal of Personality, 80(5), 1314-1338. doi:10.1111/j.14676494.2011.00760.x

Zentner, N. \& Bates, J.E. (2008). Child temperament: An integrative review of concepts, research programs, and measures. European Journal of Developmental Science, 2, 7-37. Retrieved from http://www.unige .ch/fapse/emotion/tests/temperament/publications/ejds_02_01_zentner.pdf 